\title{
Vitamin D intake of Dutch infants from the combination of (fortified) foods, infant formula, and dietary supplements
}

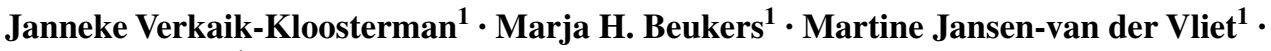 \\ Marga C. Ocké ${ }^{1}$
}

Received: 7 May 2015 / Accepted: 9 November 2015 / Published online: 24 November 2015

(c) The Author(s) 2015. This article is published with open access at Springerlink.com

\begin{abstract}
Purpose Due to changes in the Dutch fortification policy for vitamin $\mathrm{D}$ and the vitamin $\mathrm{D}$ supplementation advice for infants $(10-\mu \mathrm{g} / \mathrm{d}$ for $0-4$ year olds), a partially virtual scenario study was conducted to evaluate the risk of excessive vitamin D intake assigning all infants to a $100 \%$ adherence to the supplementation advice and considering the current fortification practice.

Methods Food consumption data from the Nutrition Intake Study (2002; $N=941,7-19$ months) were combined with Dutch food composition data from 2011 to estimate vitamin D intake from (fortified) foods. For infants 0-6 months of age, the consumption volume infant formula was estimated from energy requirement and body weight. All subjects were assigned to take a daily $10 \mu \mathrm{g}$ vitamin D supplement, according the Dutch supplementation advice for infants. Habitual vitamin D intake was estimated using the Statistical Program to Assess Dietary Exposure and compared with the tolerable upper intake levels (ULs) set by the European Food Safety Authority.

Results The median habitual total vitamin D intake was 16-22 $\mu \mathrm{g} /$ day for infants aged 0-6 months (increasing with age) and 13-21 $\mu \mathrm{g} / \mathrm{day}$ for infants aged 7-19 months (decreasing with age). About 4-12\% of infants aged 7-11 months exceeded the UL. At the 99th percentile, the intake was 2-4 $\mu \mathrm{g}$ above the UL, depending on age. Infants aged 0-6 and 12-19 months did not exceed the UL.

Conclusions In case of combined intake from infant formula, (fortified) foods, and supplements, vitamin D intakes
\end{abstract}

Janneke Verkaik-Kloosterman

Janneke.Verkaik@RIVM.nl

1 National Institute for Public Health and the Environment, PO Box 1, 3720 BA Bilthoven, The Netherlands above the UL are possible among some infants during a limited time period.

Keywords Vitamin D - Infant - Excessive intake · Food · Supplements · Infant formula

$\begin{array}{ll}\text { Abbreviations } \\ \text { UL } & \text { Tolerable upper intake level } \\ \text { SPADE } & \text { Statistical Program to Assess Dietary Exposure } \\ \text { EFSA } & \text { European Food Safety Authority } \\ \text { IoM } & \text { Institute of Medicine } \\ \text { NethFIR } & \text { Netherlands Food Information Resource } \\ \text { NEVO } & \text { Dutch food composition database (in Dutch } \\ & \text { NEderlands VOedingstoffenbestand) } \\ \text { VIO } & \text { Nutrient Intake Study (in } \\ & \text { VoedingsstoffenInnameOnderzoek) } \\ \text { AI } & \text { Adequate intake }\end{array}$

\section{Introduction}

Vitamin D is important for the development of strong bones. Serious vitamin D deficiency in infants leads to rickets $[1,2]$. The Health Council of the Netherlands set the adequate intake (AI) for infants at $10 \mu \mathrm{g} /$ day (i.e. $400 \mathrm{IU} /$ day) [1]. Too high vitamin $\mathrm{D}$ intake, on the other hand, should be prevented as this may result in risk of hypercalcaemia or hypercalciuria and kidney problems. Both the European Food Safety Authority (EFSA) and the Institute of Medicine (IoM) set a tolerable upper intake level (UL) for vitamin D [2,3]. For infants 0-6 months of age, the UL is set at $25 \mu \mathrm{g} /$ day by both EFSA and IoM, and for older infants (6-12 months), the UL is set at $25 \mu \mathrm{g}$ /day by EFSA and $37.5 \mu \mathrm{g} /$ day by IoM $[2,3]$. The UL for children aged 
1 year and older is set at $50 \mu \mathrm{g} /$ day by EFSA and at $63 \mu \mathrm{g} /$ day by the IoM $[2,3]$.

Vitamin D can be synthesised in the skin by exposure to sunlight. The actual production depends on many factors including latitude, season, time of the day, and exposure duration. In the Netherlands at $52^{\circ}$ northern latitude, vitamin D production by the skin is possible between March and November at moments the zenith angle is not oblique (i.e. $\left.>45^{\circ}\right)[1,4,5]$. However, infants should be protected from direct sunlight exposure to avoid sunburn and reduce the risk of skin cancer in later life [6]. Consequently, infants rely mostly on their diet for an adequate vitamin D supply.

Vitamin D is naturally present in foods. In addition, vitamin $\mathrm{D}$ may be added to foods like infant or follow-on formula [7]. There is a history of addition of vitamin D to margarines and baking fats (covenant between Ministry of Health and manufacturers $[8,9])$, generally with a level of $7.5 \mu \mathrm{g} / 100 \mathrm{~g}$. And since 2007, voluntary fortification of other foods is permitted in the Netherlands up to a maximum of $4.5 \mu \mathrm{g} / 100 \mathrm{kcal}[10,11]$.

Similar to other countries (e.g. [12, 13]), the Dutch Health Council advices vitamin D supplementation for children up to 4 years of age [14], in order to compensate for the minimal exposure to sunlight and generally limited vitamin D levels in food. Since 2008, the advice was to give daily a supplement with $10 \mu \mathrm{g}$ vitamin $\mathrm{D}$ for all young children ( $0-4$ years), except those consuming more than $500 \mathrm{ml}$ infant formula a day [14]. To improve the use of adequate vitamin D supplementation in the group of infants transferring from infant formula to regular milk, the supplementation advice was revised in 2012 to $10 \mu \mathrm{g}$ /day for all children up to 4 years of age, irrespective of their diet [1].

The vitamin D intake of infants may aggregate from different sources, and as such, infants may be at risk of too high vitamin D intakes. The objective of this study was to estimate the total vitamin D intake of infants for the scenario that all infants adhere to the current supplementation advice and the current practice regarding food fortification, and to investigate the risk of excessive intakes.

\section{Subjects and methods}

\section{Food consumption data}

\section{Infants aged 0 until 6 months}

For infants aged 0 until 6 months, no food consumption data are available in the Netherlands. Therefore, for infants of this age an estimation of the consumption volume of infant formula was made based on energy requirement [15] and body weight from the Dutch growth study [16]. The energy requirement was set at $0.39 \mathrm{MJ}$ per kg body weight for infants aged 0-2 months and at $0.35 \mathrm{MJ}$ per $\mathrm{kg}$ body weight for infants aged 3-5 months. The median and 97.5th percentile of the body weight distribution of Dutch infants of different ages (Table 1) were combined with these energy requirements to estimate the energy requirement in $\mathrm{MJ} / \mathrm{d}$ as an indicator of the energy intake per day as a proxy for children with median and high energy intake. The legal range of energy content of infant formula
Table 1 Estimation of the vitamin D intake ( $\mu \mathrm{g} /$ day) for Dutch infants aged 0-6 months based on energy requirement [15] and body weight (bw) [16], including and excluding the advice of a daily supplement (suppl) containing $10 \mu \mathrm{g}$ vitamin D [1]

\begin{tabular}{|c|c|c|c|c|c|c|c|c|c|}
\hline \multirow{3}{*}{$\begin{array}{l}\text { Age } \\
\text { (months) }\end{array}$} & \multirow{3}{*}{$\begin{array}{l}\text { Energy } \\
\text { requirement } \\
(\mathrm{kcal} / \mathrm{kg} \mathrm{bw})\end{array}$} & \multirow{2}{*}{\multicolumn{2}{|c|}{$\begin{array}{l}\text { Body } \\
\text { weight (kg) }\end{array}$}} & \multirow{2}{*}{\multicolumn{2}{|c|}{$\begin{array}{l}\text { Energy } \\
\text { intake } \\
\text { (kcal/d) }\end{array}$}} & \multicolumn{4}{|c|}{ Vitamin D intake ( $\mu \mathrm{g} /$ day) } \\
\hline & & & & & & \multicolumn{2}{|c|}{ P50 bw } & \multicolumn{2}{|c|}{ P97.5 bw } \\
\hline & & $\mathrm{P} 50$ & P97.5 & P50 & P97.5 & & $\begin{array}{l}+10 \mu \mathrm{g} \text { from } \\
\text { suppl }\end{array}$ & & $\begin{array}{l}+10 \mu \mathrm{g} \text { from } \\
\text { suppl }\end{array}$ \\
\hline \multicolumn{10}{|l|}{ Boys } \\
\hline $0-1$ & 93 & 3.9 & 4.9 & 363 & 456 & 6.7 & 16.7 & 8.4 & 18.4 \\
\hline $1-2$ & 93 & 4.7 & 5.9 & 438 & 550 & 8.1 & 18.1 & 10.1 & 20.1 \\
\hline $2-3$ & 84 & 5.5 & 6.8 & 460 & 568 & 8.5 & 18.5 & 10.5 & 20.5 \\
\hline $3-4$ & 84 & 6.2 & 7.7 & 518 & 644 & 9.6 & 19.6 & 11.9 & 21.9 \\
\hline $4-5$ & 84 & 7.1 & 8.8 & 594 & 736 & 11.0 & 21.0 & 13.6 & 23.6 \\
\hline $5-6$ & 84 & 7.6 & 9.5 & 635 & 794 & 11.7 & 21.7 & 14.7 & 24.7 \\
\hline \multicolumn{10}{|l|}{ Girls } \\
\hline $0-1$ & 93 & 3.7 & 4.6 & 345 & 428 & 6.4 & 16.4 & 7.9 & 17.9 \\
\hline $1-2$ & 93 & 4.4 & 5.5 & 410 & 512 & 7.6 & 17.6 & 9.5 & 19.5 \\
\hline $2-3$ & 84 & 5.1 & 6.3 & 426 & 527 & 7.9 & 17.9 & 9.7 & 19.7 \\
\hline $3-4$ & 84 & 5.7 & 7.1 & 476 & 594 & 8.8 & 18.8 & 11.0 & 21.0 \\
\hline $4-5$ & 84 & 6.6 & 8.2 & 552 & 685 & 10.2 & 20.2 & 12.7 & 22.7 \\
\hline $5-6$ & 84 & 7.1 & 8.8 & 594 & 736 & 11.0 & 21.0 & 13.6 & 23.6 \\
\hline
\end{tabular}


is $60-70 \mathrm{kcal} / 100 \mathrm{ml}$ [17]. In this study, the midpoint of $65 \mathrm{kcal} / 100 \mathrm{ml}$ was used to estimate the consumption volume of infant formula per day ( $\mathrm{ml} /$ day) from the estimated daily energy intake.

\section{Infants aged 7-19 months}

Data of the Nutrient Intake Study (VIO study) were used as source of the consumed foods of Dutch infants. This survey is the most recent Dutch survey among infants aged 7-19 months $(N=941$, response rate $82.5 \%)$ and has been described in detail elsewhere $[18,19]$. Briefly, data were collected between January and June 2002 among a representative sample of Dutch infants. Healthy, non-breastfed, term-born infants (37-41 weeks of pregnancy) with a birth weight of at least $2500 \mathrm{~g}$ were recruited via 33 Dutch child health centres (circa $95 \%$ of children ( $0-4$ years) visit these centres; between 0 and 1 year, this proportion is even higher [20]), in three age groups: 9 (7-10) months, 12 (11-13) months, and 18 (17-19) months $(n=333$, $n=306, n=302$, respectively). Data on food consumption were collected on two non-consecutive days (preferably on 1 week and one weekend day) by a diary filled in by the parents or caretakers. Several household measures (e.g. teaspoon, measuring jug) were supplied to assist the reporting of the consumed amounts. To be able to estimate the nutrient intake, the consumed foods were coded according to the Dutch food composition database 2001 [21].

\section{Scenario}

Due to the changed Dutch fortification policy for vitamin D and the changed supplementation advice for infants, a scenario was designed to estimate the potential total vitamin D intake. In this scenario (a), the vitamin D intake from food was estimated for the 2011 situation applying the 2011 fortification practice to the 2002 food consumption data (see below). In an additional scenario (b), next to vitamin D intake from foods (scenario a), all infants were assigned to a $100 \%$ adherence to the use of a daily supplement containing $10 \mu \mathrm{g}$ vitamin $\mathrm{D}$ conforming the supplementation advice for infants in the Netherlands.

\section{Food composition}

End 2011 we made an inventory of vitamin D fortified foods intended for young children ( $0-4$ years) available on the Dutch market. For this inventory, information available in the Netherlands Food Information Resource (NethFIR) containing the Dutch food composition database (NEVO; using the databases of 2006 and 2011) [22, 23] and a web application for brand foods (www.levensmiddelendatabank.nl) was used. Also, a supermarket inventory was held and searches were done on manufacturer's websites and the INNOVA database (www.innovadatabase.com). The total vitamin D content as labelled was collected for all vitamin D fortified foods.

Originally, the food consumption data from VIO were combined with Dutch food composition data from 2001 [21]. However, to get insight into the current vitamin D intake, including the current fortification practice, for this study the food consumption data were combined with Dutch food composition data from 2011 (www.rivm.nl/ nevo) supplemented with the results from the inventory. For foods coded with a code no longer present in 2011, the vitamin D content of a similar food was used. If there were more possibilities for similar foods, the one with the highest vitamin D content was selected. More than $75 \%$ of the food codes were replaced with more recent data. If no appropriate replacing food was available, the vitamin D content of 2001 was retained. These were mainly foods from food groups containing no or very low vitamin D levels in both 2001 and 2011, e.g. infant fruit meal, syrup.

As there was only little variation in the vitamin D content of infant formula, for infants aged 0-6 months the mean vitamin D content in infant formula from the inventory of end 2011 was used and multiplied with the estimated consumption volume of infant formula.

\section{Statistical analyses}

To estimate the vitamin D intake for infants 0-6 months of age, the volume of infant formula estimated based on energy requirement and median or 97.5th percentile of body weight distribution was multiplied with the vitamin D content of infant formula. It was assumed that these infants did not consume complementary foods. The estimated vitamin D intake was compared to the UL of $25 \mu \mathrm{g} / \mathrm{day}$ as set by EFSA [3] to assess the risk of excessive intake. For infants 7-19 months of age, the vitamin D intake was calculated by multiplying the consumed amounts of foods with the vitamin D content of these foods, resulting in a total vitamin $\mathrm{D}$ intake per subject for each study day. The consumption data were collected over a short-term period (day), and the individual consumption can vary considerably from day to day (i.e. within-person variation). Consequently, without correction for within-person variation, intake measured on a limited number of days per individual will be a poor indicator of the population habitual intake distribution (also referred to as usual intake). The use of such data in the evaluation of the risk of excessive intake may give invalid results. Therefore, the data in our study were statistically corrected for within-person variation to get the habitual vitamin D intake distribution using the Statistical Program to Assess Dietary Exposure (SPADE version 2.25) $[24,25]$. 
In the VIO study, most children consumed infant or follow-on formula on both study days or did not consume it at all. As vitamin D is added to infant and follow-on formula, it contributed largely to total vitamin D intake of consumers of these products. Consequently, the vitamin D intake distribution was multimodal. In the estimation of the habitual intake, it is assumed that the intake can be transformed to a more or less normal distribution, and this was not the case for the multimodal distribution. It was therefore not appropriate to estimate the habitual vitamin D intake distribution from the total vitamin D intake per day [19]. We therefore applied a so-called first-shrink-then-add approach [26-28] and estimated the habitual intake distribution separately for vitamin $\mathrm{D}$ from infant/follow-on formula and for vitamin D from other food sources. For vitamin D from other food sources, a 1-part model was applied, as this was consumed daily by all subjects. With a 1-part model, the habitual intake amount is modelled, not the intake frequency, as all subjects have a daily intake. For vitamin D intake from infant/follow-on formula, a 2-part model was applied as part of the infants did not consume infant/follow-on formula on the studied days. These two habitual intake distributions were combined using Monte Carlo to obtain the habitual total vitamin D intake distribution.

For scenario b, all infants were assigned to take daily a dietary supplement containing $10 \mu \mathrm{g}$ vitamin D. This amount was added to the vitamin D from other food sources, as it did not contain any within- or between-person variation. The estimation of the habitual total vitamin $\mathrm{D}$ intake distribution went via same procedure as described for scenario a.

To get insight into potential differences in habitual total vitamin D intake distributions for infants of different months of ages, the habitual intake was modelled as a function of age. This was performed separately for infants $7-13$ and 16-19 months of age, because data on infants 14 and 15 months of age were lacking. Uncertainty in modelling the habitual intake was quantified with bootstrap analyses (1000 iterations) and is reported as $95 \%$ confidence intervals around the point estimates.

The proportion of infants (7-19 months) with habitual total vitamin D intakes above the UL as set by EFSA (i.e. cut-off value of $25 \mu \mathrm{g} /$ day for infants below 1 year and of $50 \mu \mathrm{g} / \mathrm{day}$ for infants 1 year and older [3]) was calculated.

\section{Results}

\section{Inventory of vitamin D fortified foods}

In 2011, vitamin D was voluntary added to some breakfast cereals, cookies, dairy products, and drinks (Table 2). The labelled vitamin D levels (total of natural vitamin D and added level) varied from $0.74 \mu \mathrm{g} / 100 \mathrm{~g}$ in soy drink to $16.5 \mu \mathrm{g} / 100 \mathrm{~g}$ in porridge cereals. In accordance with EU legislation [29], baby foods, other than cereal-based foods, were not fortified with vitamin D. Infant formula (based on 33 products) contained on average $1.2 \mu \mathrm{g}$ (SD 0.2) vitamin $\mathrm{D}$ per $100 \mathrm{ml}$. Follow-on formula (based on 71 products) contained on average $1.4 \mu \mathrm{g}$ (SD 1.0) vitamin D per $100 \mathrm{ml}$. For both types of formula, the levels were below the legal maximum amounts of 2.5 and $3.0 \mu \mathrm{g} / 100 \mathrm{kcal}$, respectively.

\section{Vitamin D intake of infants aged 0-6 months}

Based on energy requirement [15] and body weight reported in the fourth Dutch national growth study [16], an indication of the energy intake was provided for children 0-6 months of age. Taking the median body weight, these intakes varied from $345 \mathrm{kcal} /$ day for girls aged $0-1$ month
Table 2 Overview of foods voluntarily fortified with vitamin $\mathrm{D}$ (specifically for young children) on the Dutch market (end 2011), number of foods (number of brands) within different food groups and specification of types of foods that are fortified

\begin{tabular}{|c|c|c|c|}
\hline Food group & $\begin{array}{l}\text { No. of vitamin D fortified foods } \\
\left(\text { no brand }^{\text {a }}\right)\end{array}$ & Type of food & $\mu \mathrm{g} / 100 \mathrm{~g}^{\mathrm{b}}$ \\
\hline \multirow[t]{2}{*}{ Breakfast cereals } & $14(3)$ & Porridge cereals & $5-16.5$ \\
\hline & $7(3)$ & Breakfast cereals & $1.7-10$ \\
\hline Cookies & $3(2)$ & Infant cookies & $3-10$ \\
\hline \multirow[t]{4}{*}{ Dairy products } & $11(6)$ & (Fruit) fromage frais & $0.95-1.25$ \\
\hline & $11(3)$ & Ready-to-drink milk porridge & $1-2$ \\
\hline & $1(1)$ & Yoghurt drink & 0.75 \\
\hline & $18(6)$ & Toddler milk & $0.9-2.1$ \\
\hline \multirow[t]{2}{*}{ Drinks } & $1(1)$ & Instant cacao powder & 7.1 \\
\hline & $1(1)$ & Soja drink junior & 0.74 \\
\hline
\end{tabular}


to $635 \mathrm{kcal} /$ day for boys aged 5-6 months (Table 1). This range was $428 \mathrm{kcal} /$ day for girls aged $0-1$ month to $794 \mathrm{kcal} /$ day for boys aged 5-6 month when taking the 97.5th percentile of the body weight curve (Table 1). In 2011, the vitamin D level in infant formula intended for children aged 0-6 months was about $1.8 \mu \mathrm{g} / 100 \mathrm{kcal}$, based on label information. Taking this vitamin D level, the intake ranged from $6.4 \mu \mathrm{g} /$ day for girls aged $0-1$ month using median body weight to $14.7 \mu \mathrm{g} /$ day for boys aged 5-6 months using 97.5th percentile of body weight. For the whole age group 0-6 months, estimated vitamin D intake from infant formula remained below the UL of $25 \mu \mathrm{g} / \mathrm{day}$.

Table 3 Users of follow-on formula $\mathrm{a}^{\mathrm{a}}$ in the Netherlands by age $(n$ and $\%$ of total study population)

\begin{tabular}{lrcr}
\hline Age (months) & $N$ & \multicolumn{2}{c}{ Users infant formula } \\
\cline { 3 - 4 } & & \multicolumn{1}{c}{$N$} & $\%$ \\
\hline 7 & 19 & 18 & 95 \\
8 & 117 & $112^{\mathrm{b}}$ & 96 \\
9 & 178 & $171^{\mathrm{c}}$ & 96 \\
10 & 48 & 44 & 92 \\
11 & 193 & $144^{\mathrm{d}}$ & 75 \\
12 & 72 & $32^{\mathrm{b}}$ & 44 \\
13 & 12 & 4 & 33 \\
16 & 26 & 3 & 12 \\
17 & 88 & 14 & 16 \\
18 & 150 & $19^{\mathrm{e}}$ & 13 \\
19 & 38 & 2 & 5 \\
\hline
\end{tabular}

a This includes infant formula marketed for infants 0-6 months of age, which was consumed by small part of the infants

${ }^{\mathrm{b}}$ One child one-day use

c Two children one-day use

${ }^{d}$ Eight children one-day use

e Four children one-day use
Also with the addition of a daily supplement containing $10 \mu \mathrm{g}$ vitamin $\mathrm{D}$, intakes were below the UL. However, for children 4-6 months, considering the 97.5th percentile of body weight, vitamin $\mathrm{D}$ intake from infant formula and a dietary supplement was close to the UL, 22.7-24.7 $\mu \mathrm{g} /$ day (Table 1).

\section{Consumption of infant formula for infants aged 7-19 months}

The percentage of infants 7-19 months of age consuming infant formula decreased with age (Table 3). About $95 \%$ of the infants aged 7-9 months consumed infant formula, compared to $5-16 \%$ of the infants $16-19$ months of age. Most infants consuming infant formula did this on both study days. Besides the age-related decrease in the proportion of infants consuming infant formula, also the consumed volume decreased with age (Table 4). Among users of infant formula, the median habitual consumption of infant formula decreased from $592 \mathrm{ml} /$ day for infants aged 7 months to $253 \mathrm{ml} /$ day for infants aged 19 months.

\section{Vitamin D intake of infants aged 7-19 months}

In 2011, the median habitual vitamin D intake from foods only (including infant formula) decreased with age by about $75 \%$, from $10.9 \mu \mathrm{g} / \mathrm{day}$ for infants 7 months old to about $2.5 \mu \mathrm{g} /$ day for infants 16-19 months of age (Table 5; Fig. 1). Logically, the habitual vitamin D intake increased with about $10 \mu \mathrm{g}$ by the addition of the daily-advised dosage vitamin $\mathrm{D}$ from dietary supplements (Table 5). The habitual intake was modelled separately including and excluding a daily supplement of $10 \mu \mathrm{g}$; therefore, the observed increase was not exactly $10 \mu \mathrm{g}$ due to modelling uncertainty.
Table 4 Habitual intake distribution of follow-on formula ${ }^{\mathrm{a}}(\mathrm{ml} /$ day) for infants aged $7-13$ and $16-19$ months consuming infant formula on at least one study day, in the Netherlands. Presented as point estimate with between brackets $95 \% \mathrm{CI}$

\begin{tabular}{llllll}
\hline Age (months) & P5 & P25 & P50 & P75 & P95 \\
\hline 7 & $348(319-429)$ & $490(466-567)$ & $592(569-667)$ & $695(670-771)$ & $846(815-927)$ \\
8 & $315(290-372)$ & $457(439-509)$ & $558(541-607)$ & $660(641-706)$ & $810(784-858)$ \\
9 & $283(261-336)$ & $424(406-474)$ & $524(507-572)$ & $626(604-672)$ & $775(744-821)$ \\
10 & $251(228-307)$ & $391(371-442)$ & $490(470-541)$ & $592(566-640)$ & $741(707-791)$ \\
11 & $220(198-277)$ & $358(338-412)$ & $457(436-509)$ & $558(534-609)$ & $706(671-758)$ \\
12 & $189(163-252)$ & $325(301-386)$ & $424(396-485)$ & $524(493-584)$ & $671(632-736)$ \\
13 & $159(128-249)$ & $293(261-385)$ & $391(355-481)$ & $490(450-582)$ & $637(588-730)$ \\
16 & $165(109-300)$ & $291(219-423)$ & $398(305-546)$ & $519(386-709)$ & $718(513-973)$ \\
17 & $132(91-241)$ & $247(204-337)$ & $346(288-442)$ & $461(360-583)$ & $650(464-838)$ \\
18 & $103(57-209)$ & $205(159-297)$ & $298(242-384)$ & $405(312-508)$ & $586(408-733)$ \\
19 & $77(30-204)$ & $168(100-300)$ & $253(171-382)$ & $353(248-484)$ & $524(357-686)$ \\
\hline
\end{tabular}

a This includes infant formula marketed for infants 0-6 months of age, which was consumed by small part of the infants 
Table 5 Habitual vitamin D intake ( $\mu \mathrm{g} /$ day) distribution (5th, 50th, 95th percentile) from foods, including and excluding a daily supplement of $10 \mu \mathrm{g}$ for infants aged $7-13$ and $16-19$ months in the Netherlands

\begin{tabular}{|c|c|c|c|c|c|c|c|}
\hline \multirow[t]{3}{*}{ Age (months) } & \multirow[t]{3}{*}{$\mathrm{UL}(\mu \mathrm{g} /$ day $)$} & \multicolumn{6}{|c|}{ Habitual vitamin D intake ( $\mu \mathrm{g} /$ day) } \\
\hline & & \multicolumn{3}{|c|}{ Food sources only } & \multicolumn{3}{|c|}{ Food and daily supplement of $10 \mu \mathrm{g}$} \\
\hline & & P5 & P50 & P95 & P5 & $\mathrm{P} 50$ & P95 \\
\hline 7 & 25 & $4.9(1.4-7.4)$ & $10.9(9.9-11.9)$ & $16.7(15.2-18.0)$ & $14.7(11.6-17.2)$ & $21.1(20.2-22.2)$ & $26.5(25.5-27.7)$ \\
\hline 8 & 25 & $4.9(3.3-6.2)$ & $10.5(10.2-11.3)$ & $16.2(15.8-17.3)$ & $14.6(13.4-16.1)$ & $20.6(20.3-21.6)$ & $26(25.6-27.1)$ \\
\hline 9 & 25 & $5(3.6-5.9)$ & $10.1(9.8-11.0)$ & $16(15.6-16.9)$ & $14.6(13.6-15.7)$ & $20.3(20-21.1)$ & $25.8(25.2-26.6)$ \\
\hline 10 & 25 & $3.7(2.1-5.5)$ & $9.6(9.2-10.5)$ & $15.8(15.1-16.6)$ & $13.7(12.3-15.4)$ & $19.9(19.3-20.6)$ & $25.3(24.7-26.2)$ \\
\hline 11 & 25 & $1.3(1.1-1.7)$ & $8.3(7.8-9.2)$ & $14.8(14.3-15.8)$ & $11.5(11.2-11.9)$ & $18.3(17.8-19.3)$ & $24.5(23.9-25.4)$ \\
\hline 12 & 50 & $0.8(0.6-1.1)$ & $5.7(4.4-6.8)$ & $13.5(12.4-14.5)$ & $10.7(10.3-11)$ & $15.4(14.5-16.7)$ & $23(22.2-24.2)$ \\
\hline 13 & 50 & $0.8(0.4-1.2)$ & $4.6(3.1-7.0)$ & $12.6(9.6-14.7)$ & $10.6(9.7-11.2)$ & $14.6(13.1-17.0)$ & $22.1(18.9-24.2)$ \\
\hline 16 & 50 & $0.5(0.2-0.6)$ & $2.4(1.5-3.0)$ & $9.7(6.3-12.0)$ & $9.6(8.8-10.0)$ & $13(11.8-13.5)$ & $19.1(16.2-21.7)$ \\
\hline 17 & 50 & $0.5(0.4-0.6)$ & $2.6(2.3-3.2)$ & $9.8(8.3-12.1)$ & $9.7(9.5-10.1)$ & $13.1(12.8-13.7)$ & $19.1(17.8-21.2)$ \\
\hline 18 & 50 & $0.5(0.5-0.6)$ & $2.6(2.3-3.1)$ & $9(8.1-10.5)$ & $9.7(9.5-10.1)$ & $13(12.7-13.5)$ & $18.4(17.4-19.6)$ \\
\hline 19 & 50 & $0.5(0.3-0.7)$ & $2.5(1.6-3.0)$ & $8.5(5.9-10.1)$ & $9.7(9-10.1)$ & $12.9(12-13.4)$ & $17.6(15.9-18.7)$ \\
\hline
\end{tabular}

Results are presented as point estimate and between brackets $95 \% \mathrm{CI}$

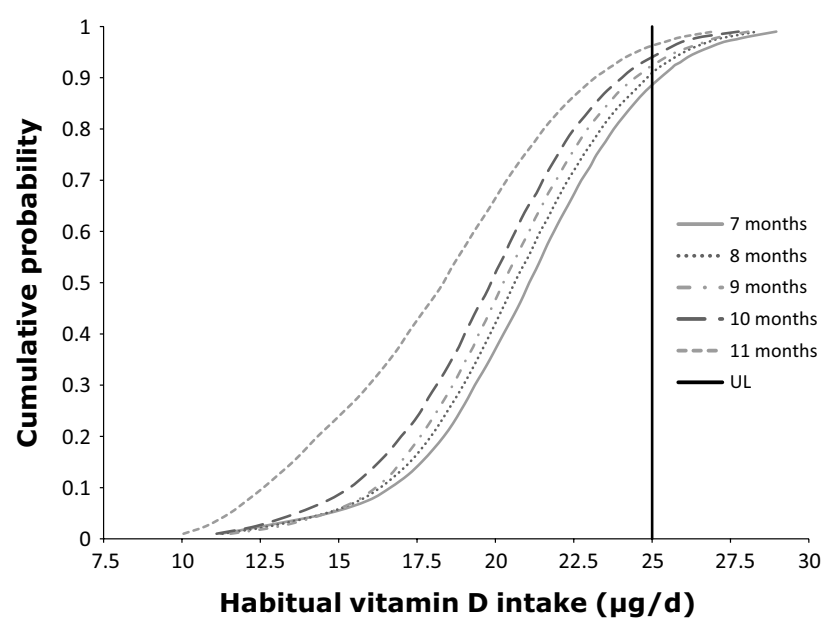

Fig. 1 Habitual infant vitamin D intakes distribution ( $\mu \mathrm{g} / \mathrm{day})$ from food and dietary supplements (as advised) and position towards the $\mathrm{UL}$ of $25 \mu \mathrm{g} /$ day as set by EFSA [3]

\section{Comparison with the $U L$}

The vitamin D intake from foods only remained below the UL for all ages (data not shown). Including a daily supplement containing $10 \mu \mathrm{g}$ vitamin $\mathrm{D}, 4-11 \%$ of the infants 7-11 months old had intakes exceeding the UL of $25 \mu \mathrm{g} /$ day (Fig. 2). This percentage decreased with age. The vitamin D intake at the 99th percentile was 27-29 $\mu$ g vitamin D per day for infants $7-11$ months of age. For infants 12-13 and 16-19 months old, the total vitamin D intake remained below the UL of $50 \mu \mathrm{g} /$ day.

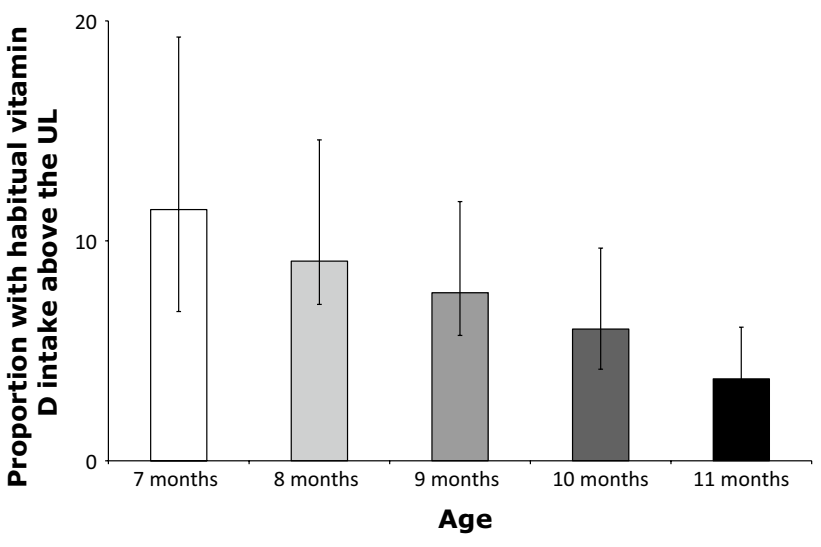

Fig. 2 Proportion of infants (7-11 months of age) with vitamin D intakes from foods and the advised supplement dosage of $10 \mu \mathrm{g} / \mathrm{day}$ exceeding the UL of $25 \mu \mathrm{g} /$ day [3]

\section{Discussion}

The scenario study presented in this paper suggests that infants aged 0-6 months and 1 year and older are not at risk of exceeding the UL for vitamin D by combined intake from food and supplements (according to the supplement advice). Our study suggests, however, that some infants aged 7-11 months of age are at risk of exceeding the UL for vitamin D as set by EFSA by combined intake of vitamin D from regular food, infant formula, fortified foods, and supplements. Some of these infants still consume considerable amounts of infant formula sometimes combined with fortified foods. Together with following the current 
Dutch supplementation advice of $10 \mu \mathrm{g} /$ day, this resulted in 4-11\% (decrease with age) of the infants with vitamin D intakes above the UL.

\section{Risk of adverse health effects}

For children 7-11 months old, the vitamin D intake at the 99th percentile was $27-29 \mu \mathrm{g} /$ day and decreased with age. This suggests that some infants are exceeding the UL at a limited time period of at maximum 5 months and with a limited amount (8-15\% above the UL) which decreased with age. From 1 year onwards, the UL is two times higher, namely $50 \mu \mathrm{g} / \mathrm{day}$, and no exceedances were observed. The few studies that were used for setting the UL for infants $(0-1$ year) showed no adverse effects after a duration of about 4 months to 24 weeks [30]. This time period has a similar length as the period in our study at which some infants are at risk of vitamin D intakes above the UL.

An intake above the UL will, in most cases, not directly result in harmful health effects, as in setting the UL uncertainty factors are applied and the UL is generally set for health effects presenting after chronic high exposure. In addition, the risk of harmful health effects will be determined by the duration of high intakes and the actual amounts and varies from person to person [3, 31]. Moreover, the UL for infants is surrounded by uncertainties due to lack of data. This is illustrated by the higher ULs as set by IoM [2] compared to EFSA for children aged 7 months to 3 years. In our study, the 99th percentile of total vitamin D intake remained below the IoM ULs for all infants. Given the above arguments, the results of this study are not directly alarming, but do call for studies on the relationship between high vitamin D intakes during infancy and adverse health effects. In addition, we advise to be alert on potential adverse health effects that may be related to excessive vitamin D intakes in infants and monitor the habitual vitamin D intake regularly.

\section{Accuracy using label information for food composition}

Other studies have shown that it is not uncommon that fortified foods contain higher amounts of micronutrients than declared on the package $[32,33]$. This so-called overage is applied to ensure adequate levels of the nutrient at the end of the shelf life. We are aware of few published data regarding vitamin D overages in fortified foods or dietary supplements. In 1992, vitamin D overages were observed in infant formula in USA [34]. Seven of ten samples contained more than $200 \%$ of the labelled amount. A more recent study in USA showed lower overage levels of 100$180 \%$ of labelled values in infant formula [35]. In a New Zealand study, 12 of the 18 foods (i.e. baby food, food drink, margarine, milk product) had a measured vitamin
D concentration that significantly deviated from the label claim [32]. For seven products, this was an overage. In the whole sample, the deviation ranged from -68 to $+70 \%$. In a recent update of the vitamin D content of fortified foods and supplements in the UK Nutrition Survey Nutrient Databank, for each vitamin D level on the label a standard overage of $12.5 \%$ was applied [36]. The overage at time of production was estimated to be on average $25 \%$ (manufacturer and trade association: overages ranged $20-30 \%$ for fortified foods and $20-40 \%$ for supplements). The average remaining overage at time of consumption was assumed at $50 \%$ of this $25 \%$. Taking into account, this overage of $12.5 \%$ for all vitamin D fortified foods and supplements showed a $6 \%$ increase in mean vitamin D intake in UK population aged 1.5 years and over. This proportion tended to be higher for the youngest age group (1.5-3 year), namely $9 \%$.

The importance of the fortified foods and supplements in the total vitamin D intake will influence the effect of potential overages on the intake. For infants in the Netherlands using vitamin D supplements as advised and in addition consuming fortified foods, the effect of overages on total intake might be substantial. If in this study the habitual total vitamin $\mathrm{D}$ intake from food and supplements will be increased due to overages by $9 \%$ or even $12.5 \%$ in children aged 7 months, the proportion with intakes above the UL would crudely be estimated at 30-35\% as compared to $11 \%$ based on label information. However, even at high percentiles, the crude estimate of the habitual intake would be still below the UL of $37.5 \mu \mathrm{g} /$ day as set by the IoM. It is recommended to study the overage (at time of consumption) in fortified foods and supplements, especially for products and/or nutrients contributing largely to the total nutrient intake.

\section{Intake from dietary supplements}

In our scenario, all infants were assigned to a $100 \%$ adherence to the vitamin D supplementation advice. Several studies showed that not all infants take supplements according to this advice [37-40]. In the Netherlands in 2012, the vitamin $\mathrm{D}$ supplementation advice for young children was adapted to make it unambiguous. In the new advice, all young children, despite the amounts of infant formula consumed, are advised to take a daily vitamin D supplement. There is no insight into the current vitamin D intake from supplements among children $0-4$ year old. In a recent study among children visiting day care (at least 2 and maximum 5 days per week), about $90 \%$ of the parents reported to provide vitamin $\mathrm{D}$ supplementation to their infant (10 months to 3 year) [41]. It was unclear whether dosages were provided and whether the supplement was given daily. The risk of exceeding the UL may be an overestimation if 
not all children use a vitamin D supplement daily, as it was shown that especially the combined intake from foods and supplements resulted in intakes above the UL. On the other hand, our estimate may be an underestimation if children take more vitamin D from supplements than advised [40]. Our study shows the potential risk of exceeding the UL if all children would follow the supplementation advice as is warranted in combination with available fortified foods in a realistic consumption pattern.

\section{Food consumption data}

The food consumption data used in this scenario study are from 2002. The response rate was high $(82.5 \%)$, and the data can be considered representative for the Netherlands at that time. Total energy intakes of the infants indicated that there was no major problem of under- or overestimation at the group level [19]. It is possible that the consumption pattern of infants changed during the last decade; however, no recent data are available for the Netherlands. Also for other European countries, these data are scarce [42]. To get better insight into the food consumption of infants, it is recommended to conduct a food consumption survey regularly among this age group, preferably also including the younger ages $0-6$ months and those consuming breast milk.

In our scenario study, for infants aged 0-6 months a crude estimate of vitamin D intake was made based on energy requirement and body weight. It was assumed that these infants did not consume any complementary foods; however, part of the infants younger than 6 months of age may already start consuming these foods [43]. The vitamin D intake estimated in our scenario study may be an underestimation for infants aged 3-6 months. On the other hand, the foods often started with, for example, vegetables and fruit generally do not contain large vitamin D levels. It is therefore expected that this will not affect the estimates of the vitamin D intake largely.

Originally, the VIO study was combined with Dutch food composition data from 2001. For our study, the food consumption data were combined with more recent Dutch food composition data from 2011, to reflect better the actual vitamin D intake. Based on a quick scan of the current market (2015) using similar resources as in 2011, it can be concluded that the current market of vitamin D fortified foods and supplements is comparable with the situation in 2011 (data not shown). As information was collected from several sources, we expect this inventory to be rather complete. For some foods, the highest level in a product group was applied what may lead to an overestimation. In general, the contribution of vitamin $\mathrm{D}$ fortified foods, other than infant formula, was low; therefore, the effect of this potential overestimation on the total vitamin $\mathrm{D}$ intake is considered minor. To improve the estimation of vitamin D intake, it is recommended to have an up-to-date overview of the vitamin D fortified foods available on the Dutch market including the vitamin D levels, for example, by notification.

The data of the VIO study were collected among a relative small study population in three specific age groups: about 9,12 , and 18 months. Consequently, these three ages are more represented in this study population than the surrounding ages. To get results per month of age, the habitual intake was not estimated separately per age group, but as a function of age incorporating the data of all ages. The higher uncertainty in results of the habitual intake distribution for age groups (months of age) with a small number of observations is taken into account in the $95 \%$ confidence interval. As a result, the $95 \%$ confidence intervals of age groups with a low $n$ are generally wider. Although the number of children in some age months was rather low, a clear effect of age was observed.

\section{Scenario analyses}

In this paper, we presented a scenario study. Scenario analyses are theoretical exercises only. But they provide insight into changes in the exposure distribution, where otherwise no rapid quantitative insight could be given. A number of assumptions are always needed to build scenarios, and it is important to interpret the results always in the light of these assumptions. The results are most predictive with realistic assumptions. From a policy making point of view, scenario analyses are very relevant as it may give at least some insight into what may the population impact of a (potential) change in policy. For instance, will the target population receive the adequate intake level with a specific fortification practice and is there no or limited risk of excessive intakes in the whole population. In addition, signals from scenario studies may be used to get the scope for additional research required to get more precise answers whether there is a health problem $[44,45]$.

A strength of this study was that the habitual total vitamin D intake from all potential vitamin D sources was estimated using a model that could cope with the multimodality of the data, namely a first-shrink-then-add approach. By splitting up the consumption data in vitamin D from infant/ follow-on formula and vitamin D from other sources, two uni-modal distributions were created for which the habitual intake distribution could be estimated without violation of the model assumptions. It is important that the model assumptions are met, otherwise the habitual intake distribution may be estimated invalidly (especially at the tails), and as a result, the proportion at risk of excessive intakes may be invalid [24, 26]. This approach may be applied in research facing multimodal distributions which could be identified by splitting up the data in different sources of 
intake, such as voluntary fortification practices and intake from dietary supplements.

\section{Conclusion}

In conclusion, infants aged 0-6 months and 1 year and older were not at risk of exceeding the UL. Some infants $7-11$ months of age are at risk of vitamin D intakes above the UL with combined consumption from infant formula, (fortified) foods, and supplements. The largest risk is for 7-month-olds still consuming relatively large amounts of infant formula. It remains unclear whether a temporarily exceedance of the UL with a limited amount may cause harmful effects in infants at short or long term. Additional research is recommended for the association between high vitamin D intake and harmful health effects in infants. In addition, more insight is required in the actual vitamin D content of foods with added vitamin D and dietary supplements to study whether label information can be used for valid estimations of dietary intake or that correction for potential overages is required. Nonetheless, this partially virtual scenario study illustrates the possibility of vitamin D intake of older infants beyond the UL set by EFSA.

\section{Compliance with ethical standards}

Conflict of interest On behalf of all authors, the corresponding author states that there is no conflict of interest.

Open Access This article is distributed under the terms of the Creative Commons Attribution 4.0 International License (http://creativecommons.org/licenses/by/4.0/), which permits unrestricted use, distribution, and reproduction in any medium, provided you give appropriate credit to the original author(s) and the source, provide a link to the Creative Commons license, and indicate if changes were made.

\section{References}

1. Health Council of the Netherlands (2012) Evaluation of the dietary reference values for vitamin D. Health Council of the Netherlands, The Hague

2. Institute of Medicine (2011) Dietary reference intakes for calcium and vitamin D. The National Academies Press, Washington, DC, USA

3. EFSA Panel on Dietetic Products NaA (2012) Scientific opinion on the tolerable upper intake level of vitamin D. EFSA $J$ 10(7): $1-45$

4. Webb AR, Kline L, Holick MF (1988) Influence of season and latitude on the cutaneous synthesis of vitamin D3: exposure to winter sunlight in Boston and Edmonton will not promote vitamin D3 synthesis in human skin. J Clin Endocrinol Metab 67(2):373-378

5. Holick MF (2004) Sunlight and vitamin D for bone health and prevention of autoimmune diseases, cancers, and cardiovascular disease. Am J Clin Nutr 80(6 Suppl):1678S-1688S

6. WHO (2013) Individual protection against UV. WHO. http://www. who.int/uv/faq/protect/en/index10.html. Accessed 19 Nov 2015
7. Anonymous (2006) Commission directive 2006/141/EC of 22 December 2006 on infant formulae and follow-on formulae and amending Directive 1999/21/EC. Off J Eur Union L 49:1-33

8. Anonymous (1999) Convenant Vitaminering van Smeerbare vetproducten (GZB/VVB/997542). www.mvo.nl

9. Kraak H (2004) Convenant verlengd. Fabrikanten blijven vrijwillig vitamine $\mathrm{A}$ en $\mathrm{D}$ toevoegen aan smeervetten. Voeding $\mathrm{Nu}$ 6(2):14-15

10. Kloosterman J, Fransen HP, de Stoppelaar J, Verhagen H, Rompelberg C (2007) Safe addition of vitamins and minerals to foods: setting maximum levels for fortification in the Netherlands. Eur J Nutr 46(4):220-229. doi:10.1007/s00394-007-0654-y

11. Anonymous (2007) Warenwetregeling vrijstelling toevoeging foliumzuur en vitamine D aan levensmiddelen. Staatscourant 12:11-12

12. Health Canada (2012) Nutrition for healthy term infants: recommendations from birth to six months. Health Canada. http:// www.hc-sc.gc.ca/fn-an/nutrition/infant-nourisson/recom/indexeng.php. Accessed 19 Nov 2015

13. UK Health Departments (2012) Vitamin D-advice on supplements for at risks groups. Department of Health of government of UK. http://webarchive.nationalarchives.gov. uk/20130107105354/http://www.dh.gov.uk/prod_consum_dh/ groups/dh_digitalassets/@dh/@en/documents/digitalasset/ dh_132508.pdf. Accessed 19 Nov 2015

14. Health Council of the Netherlands (2008) Towards an adequate intake of vitamin D. vol publication no. 2008/15. Health Council of the Netherlands, The Hague

15. Health Council of the Netherlands (2001) dietary reference intakes: energy, proteins, fats and digestible carbohydrates, vol publication no. 2001/19R (corrected edition: June 2002). Health Council of the Netherlands, The Hague

16. Fredriks AM, van Buuren S, Burgmeijer RJ, Meulmeester JF, Beuker RJ, Brugman E, Roede MJ, Verloove-Vanhorick SP, Wit JM (2000) Continuing positive secular growth change in The Netherlands 1955-1997. Pediatr Res 47(3):316-323

17. Anonymous (2006) Richtlijn 2006/141/EG van de Commissie van 22 december 2006 inzake volledige zuigelingenvoeding en opvolgzuigelingenvoeding en tot wijziging van Richtlijn 1999/21/EG. Publicatieblad van de Europese Unie L401:1-33

18. Breedveld BC, Hulshof K (2002) Zo eten jonge peuters in Nederland. Resultaten van het Voedingsstoffen Inneming Onderzoek 2002. Voedingscentrum \& TNO, DenHaag \& Zeist

19. De Boer EJ, Hulshof KFAM, ter Doest D (2006) Voedselconsumptie van jonge peuters. TNO, Zeist

20. Statistics Netherlands (2014) Parents give child health centers a 7 out of 10. Statistics Netherlands. http://www.cbs.nl/ en-GB/menu/themas/gezondheid-welzijn/publicaties/artikelen/ archief/2014/2014-4147-wm.htm?Languageswitch $=$ on . Accessed 19 Nov 2015

21. NEVO foundation/Stichting NEVO (2001) NEVO table 2001, Dutch Food Composition Database. Netherlands Bureau for Nutrition Education, The Hague

22. NEVO Foundation/Stichting NEVO (2006) NEVO table 2006, Dutch Food Composition Database. Netherlands Bureau for Nutrition Education, The Hague

23. RIVM (2011) NEVO-tabel. Nederlands Voedingsstoffenbestand 2011. Den Haag

24. Dekkers AL, Verkaik-Kloosterman J, van Rossum CT, Ocke MC (2014) SPADE, a new statistical program to estimate habitual dietary intake from multiple food sources and dietary supplements. J Nutr 144(12):2083-2091. doi:10.3945/jn.114.191288

25. Souverein OW, Dekkers AL, Geelen A, Haubrock J, de Vries JH, Ocke MC, Harttig U, Boeing H, van't Veer P (2011) Comparing four methods to estimate usual intake distributions. Eur J Clin Nutr 65(Suppl 1):S92-101. doi:10.1038/ejcn.2011.93 
26. Verkaik-Kloosterman J, Dodd KW, Dekkers AL, van't Veer P, Ocke MC (2011) A three-part, mixed-effects model to estimate the habitual total vitamin $\mathrm{D}$ intake distribution from food and dietary supplements in Dutch young children. J Nutr 141(11):2055-2063. doi:10.3945/jn.111.142398

27. Dodd KW, Bailey R, Wilger J, Sempos C, Dwyer J, Radimer K, McDowell M, Johnson C, Picciano MF (2009) Estimating distributions of usual total nutrient intake: a comparison of available methods. In: 7th international conference on diet and activity methods (ICDAM), Washington, DC

28. Garriguet D (2009) Challenges in combining food and supplement intake data using the Canadian Community Health Survey-Nutrition. In: 7th international conference on diet and activity methods (ICDAM), Washington, DC

29. Commission Directive 2006/125/EC (2006) Processed cerealbased foods and baby foods for infants and young children. Off $\mathbf{J}$ Eur Union L339:16-35

30. Scientific Committee on Food, Scientific Panel on Dietetic Products Nutrition and Allergies (2006) Tolerable upper intake levels for vitamins and minerals. European Food Safety Authority

31. Carriquiry AL, Camano-Garcia G (2006) Evaluation of dietary intake data using the tolerable upper intake levels. J Nutr 136(2):507S-513S

32. Thomson B (2006) Fortification overages of the food supply. Vitamin A, vitamin D and calcium. Insitute of Environmental Science and Research Limited (ESR), Christcurch, New Zealand

33. MacLean WC, Van Dael P, Clemens R, Davies J, Underwood E, O'Risky L, Rooney D, Schrijver J (2010) Upper levels of nutrients in infant formulas: comparison of analytical data with the revised Codex infant formula standard. J Food Compos Anal 23:44-53

34. Holick MF, Shao Q, Liu WW, Chen TC (1992) The vitamin D content of fortified milk and infant formula. N Engl J Med 326(18):1178-1181. doi:10.1056/NEJM199204303261802

35. Pehrsson PR, Patterson KY, Khan MA (2014) Selected vitamins, minerals and fatty acids in infant formulas in the United States. J Food Compos Anal 36:66-71

36. Allen RE, Dangour AD, Tedstone AE (2014) Update of the vitamin $\mathrm{D}$ content of fortified foods and supplements in the UK National Diet and Nutrition Survey Nutrient Databank. Nutr Bull $39: 247-252$
37. De Nooijer J, Jansen R, Van Assema P (2012) The use of implementation intentions to promote vitamin $\mathrm{d}$ supplementation in young children. Nutrients 4(10):1454-1463. doi:10.3390/ nu4101454

38. de Nooijer J, Onnink M, van Assema P (2010) Vitamin D supplementation in young children: associations with theory of planned behaviour variables, descriptive norms, moral norms and habits. Public Health Nutr 13(8):1279-1285. doi:10.1017/ S1368980010000777

39. van der Linden-Kuiper AT, Bunge-van Lent FC, BoereBoonekamp MM (1999) Recommendations of vitamin D supplements for toddlers frequently disregarded. Ned Tijdschr Geneeskd 143(43):2146-2150

40. Ocké MC, Van Rossum CTM, Fransen HP, Buurma EJM, De Boer EJ, Brants HAM, Niekerk EM, Van der laan JD, Drijvers JJMM, Ghameshlou Z (2008) Dutch National Food Consumption Survey-Young Children 2005/2006, vol RIVM Report 350070001/2008. RIVM, Bilthoven

41. De Jong-Rubingh C, Bausche-Goldbohm RA (2015) De Eet Compleet Test: 2-daags voedselconsumptie onderzoek onder kinderen van 1-4 jaar die een kinderdagverblijf bezoeken. TNO, Zeist

42. European Food Safety Authority (2011) Guidance of EFSA: use of the EFSA Comprehensive European Food Consumption Database in Exposure Assessment. EFSA J 9(3):2097

43. Tromp II, Briede S, Kiefte-de Jong JC, Renders CM, Jaddoe VW, Franco OH, Hofman A, Raat H, Moll HA (2013) Factors associated with the timing of introduction of complementary feeding: the Generation R Study. Eur J Clin Nutr 67(6):625-630. doi:10.1038/ejen.2013.50

44. Verkaik-Kloosterman J (2011) Estimation of micronutrient intake distributions. Development of methods to support food and nutrition policy making. Wageningen University, Wageningen

45. Martiniak Y, Heuer T, Hoffmann I (2015) Intake of dietary folate and folic acid in Germany based on different scenarios for food fortification with folic acid. Eur J Nutr 54(7):1045-1054. doi:10.1007/s00394-014-0781-1 